\title{
15. VISUAL RESEARCH METHODS AND NEW MASCULINE SUBJECTIVITIES
}

\section{INTRODUCTION}

This chapter reflects on photovoice, a creative and participatory visual research methodology employed to enquire into the relationship between ideals of masculinity and fathers' experience of family literacy learning care-work (FLLC). Finding a research methodology that uncovers the nuances and complexities of social experience is not a simple task. It requires careful consideration of multiple elements, including the rich diversity of humankind, the wider social, political, affective and cultural context in which the research is taking place and the researcher's own positionality. In the field of adult education research there is strong emphasis on enquiring into the nature of social reality with people. Hence relationships built through listening to the 'other' are central to the research process and listening requires attention to voice. The photovoice methodology is premised on the assumption that people's voices are infused with knowledge that outsiders, like myself, lack (Wang \& Burris, 1997).

I open the chapter with a discussion of my approach to research and how the research methodology was chosen. Details of photovoice as a powerful participatory research method follow. The chapter proceeds with an account of the study, briefly introduces the research participants and reflects on the experience of finding this way to research. I propose that the photovoice methodology engaged participants in a creative and critical adult education process. It gave rise to nuanced, insightful conversations about the social experience of the gendered and classed construction of masculinity, fatherhood and family learning care work.

\section{RESEARCH APPROACH}

I am a feminist activist, researcher and adult education practitioner. I passionately believe in the power of critical adult education to transform lives and to challenge a destructive status quo that is maintained and reproduced by unequal gendered and classed social structures. My practice is anchored in a worldview that has been deeply influenced by the work of Freire $(1972,1997)$ and feminist education scholars (see Connolly, 2008; hooks, 1994; Reay, 1998) who trust in the importance of everyday knowledge and value people as knowing subjects with the capacity to make decisions about their lives. For me, the work of adult education is a creative and collective process which has greater social justice as its goal. Critical adult 
education sets out to illuminate and challenge oppressive social structures which seek to limit and constrict our potential rather than supporting human flourishing. I understand creativity in research and pedagogy as a process that welcomes and enables participation and development by people who have had previous harmful encounters within the education system. Creativity, like adult education itself, involves effort and builds on the ability to see more clearly and to rediscover what we know but seem to have forgotten (Jon-Steiner, 1997). Previously sedimented knowledge emerges through reflection and dialogue. Reflexivity, deliberating as a thinking subject, is a central component of creativity and a critical step in developing agency (Allen, 2002). It underpins adult education practice which seeks to support people to collectively name their world through engaging in transformative dialogue which in turn brings to light the lines of power (Dean, 1998) that both shape and connect us to one another.

\section{CHOOSING PHOTOVOICE AS A METHODOLOGY}

Finding what Connolly terms a 'really useful research methodology' (2008, p. 96) led me to investigate the use of photovoice as an engaging means of recruiting participants in my research. Based on the use of photography, it is a flexible and participative research approach and has been used extensively across a diversity of disciplines such as anthropology, education, sociology, psychology and cultural studies (Luttrell \& Chalfen, 2010). The term 'photovoice', was coined by Caroline Wang following her research into community health with rural women in China (Wang et al., 1998). The methodology is rooted in the problem-posing educational work of Freire (1972) and its goal is to contribute towards greater social justice (Mitchell, 2010).

A number of considerations and some assumptions guided my choice of photovoice. Working-class male participants are often referred to as hard to reach by social researchers and adult educators (Bengry-Howell \& Griffin, 2012; Corridan, 2002), therefore I wanted to choose a methodology that would be engaging and reciprocal. Within disparaging discourses about working-class parents, fathers are most often described in one-dimensional terms and relegated to the realms of deficit and pathology (Reay, 2004). My goal was to find a method that would reveal more nuanced understandings of fathers from working-class communities. Supporting male research participants to discuss their emotional lives is often described in the literature as challenging, photovoice has been effectively used to support men to discuss their intimate emotions and to engage in reflective and collaborative thinking (Oliffe \& Bottorff, 2007; Slutskaya et al., 2012).

The research aimed to address unequal gendered care constructs and to explore the under-researched relationship between ideals of masculinity and fathers' involvement in FLLC. Literacy and literate activities are often viewed as passive and belonging in the feminine, therefore subordinate, domain (Martino \& Berril, 2003). By association, the personal relationship some men have with literacy effects their 
involvement in family literacy learning care work (Karther, 2002; Nichols, 2002). Disparaging discourses about working-class parents depict fathers as uncaring, absent and feckless (Hewett, 2015). Yet research shows that all parents value literacy skills and regardless of parents' own literacy levels, they report that they want their children to do well and to support their learning in school (Hegarty \& Feeley, 2010).

Consideration of the research context was also paramount: In Ireland, as the recession deepened, high levels of unemployment spread across the male-dominated construction industry (Barry \& Conroy, 2012). I planned to work with men who had moved from the public space of breadwinning to the private place of stay-at-homefather (SAHF). I expected that they might be feeling some vulnerability about their new identities. I hoped that the reflective and collective nature of the methodology would support individual men to reflect on and voice their current experiences as SAHF with their peers. Through the critical interrogation of their images it was possible that useful insights and understandings of their gendered experiences might emerge.

\section{The Photovoice Process}

Photovoice can serve to involve participants in a powerful process of telling their stories and connecting with others. In naming and showing their world to one another they are engaged in building knowledge and understanding of the social world and their place in it. Mirroring core aspects of radical adult education, the participant's perspective in photovoice is the starting point. Research participants are given cameras and asked to construct images relating to the research topic. They have time to go away and to consider and create those images. The creative activity is itself the starting point for the development of thoughts about personal experience. In the making of images participants are already involving themselves in engaged thinking.

When the group next meet, photographs are shared and participants get to view, discuss and respond to each other's images. Contrasting with more traditional one-to-one interviews where research participants may be in a more passive role, photovoice participants have autonomy about the images they choose to take and to share with the group. Whilst each photographer is the expert about the image they have constructed, individual interpretations can be puzzled over in the collective space. Images evoke open conversations about diverse topics and these are further expanded by facilitated group discussions which can illuminate different ways of being in the world. This creative process requires time and skilled facilitation.

\section{THE STUDY}

The global economic crisis resulted in some small disruption and restructuring of patriarchal, socially constructed, gendered parenting roles and such changes brought challenges and opportunities. The one-time breadwinner found himself in the 
unfamiliar role of fulltime family carer whilst his partner, often in poorly paid and part-time employment, provided financially for the family. These SAHF and their role in family learning were the focus of the photovoice study reflected upon in this chapter.

\section{Research Participants}

Existing networks within the adult literacy and community education sector in and around Dublin were used to recruit fathers to the project. Following introductory meetings four groups agreed to participate. Each group committed to three photovoice research workshops over a period of three weeks and these were located within familiar community learning settings.

In all, twenty men contributed to the research. Between them they had 56 children ranging in age from twelve months to 41 years. The youngest research participant was 27 years old whilst the oldest was 65 . Together, these fathers had a wealth and diversity of experience to draw from.

The men lived in some of the most disadvantaged areas of Dublin. These areas are characterized by multiple inequalities and state neglect that is evidenced by high levels of poor housing, long-term unemployment, educational disadvantage and ill health. Research participants had first-hand experience of such social harm, including early school leaving, drug and alcohol addiction, sexual and physical abuse, imprisonment and damaging experience of institutional care, homelessness and depression.

\section{Research Process}

Research has shown that entering a learning group can be a daunting experience for men. Many express fear about how they might be perceived by male peers (Corridan, 2002; De Brun \& Du Vivier, 2007). Levels of anxiety and embarrassment about learning in groups are further compounded by memories of early and negative school experiences (Hegarty \& Feeley, 2010). With this in mind the aim of the first workshop was to support individual participation and to develop the group working relationship.

In-depth discussion about literacy and family literacy were planned to ground the workshop in shared understandings of these pivotal themes and to establish a context for the men in thinking about taking photos of family literacy in practice. Activities relating to photography, camera skills and the reading of images that the men had taken during an initial photographic treasure hunt made up the second part of the workshop. This culminated in agreements about the rights and responsibilities associated with taking photographs with a particular emphasis on ethics and consent procedures relating to photographing children. The 'mission' for participants at the end of the first workshop was to capture images of FLLC in their families. Discussion 
and analysis of these images and the story behind their production was the focus of the second workshop. From these discussions the challenges and benefits of FLLC for men in their new role as SAHF were identified. The final workshop focused on collectively naming and questioning the source of messages about masculinity and fatherhood alongside an analysis of the impact of such messages on the men's lives. Following the photovoice workshops fifteen one-to-one interviews were conducted (Hegarty, 2017).

Once the data analysis was complete, a final research meeting with participants took place. Here emergent themes were discussed in order to strengthen the validity of the analysis. Text messaging updates to participants about the progress of the enquiry continued throughout the data-gathering phase of the study. This communication loop served to maintain the relationship with the men over time and many responded to the texts with messages of good will and continued interest in the project.

\section{Fieldwork}

Engaging in three workshops provided a stretch of time for participants to settle into the research process, to get to know one another and the researcher. Initially, within the public group-space many of the men engaged in a range of comments which established them variously as robustly heterosexual, knowledgeable about sport, photography and authoritative parenting.

In some cases, these comments intensified when the men were given cameras and sent out on a photographic treasure hunt. Cameras and photography were closely associated with pornography by some men and sexually loaded remarks, which objectified women, were casually exchanged. On their return, images were uploaded to a computer and projected onto a large screen. During this time participants had an opportunity to relax and to talk informally to one another about the cameras, their children and their lives. Conversations shifted. Men could be heard presenting themselves differently to one another in the more intimate space of one-to-one conversations. They began to speak of their concerns about their children. They shared experiences of access arrangements. One man spoke to another about his son watching pornography on the internet. Another spoke proudly of his son's sporting achievements. In these moments tentative efforts towards mutual understanding were being made, and Dad relationships were being formed.

Whilst viewing their treasure hunt photographs in the large group another conversation shift takes place where men leave aside private conversations about children and revert to public banter. Sexually loaded, misogynistic remarks are casually expressed,

Johnny Cash ${ }^{1}$ : That's a girl's bike, it's pink

Badboy: You don't know that!

Batman: Women are vain. They love themselves ... It's a substantial saddle. 
Badboy: They like themselves ... I'd say she has a big ass. She needs one of those saddles 'cause she has a Kim Kardashian backside. [Group laughter] (Transcript group 3)

Remarks made by individual men were greeted by laughter, which signified group affiliation and the construction of a mutual masculine understanding (Grønnerød, 2004). Situated in a wider context where men instinctively looked to one another for respect and recognition (Connell, 1995) displays of incontrovertible heterosexual masculine selves were most often directed towards other members of the group rather than me, an older female researcher. Nevertheless, they were not without impact on me. As a reflexive feminist researcher, I am aware, like Etherington (2004) of the rich learning to be gleaned from the researcher's personal responses. In truth it was not easy to be a lone woman amidst a group of men engaged in this sort of conversation. The words and the meanings behind them attach to other misogynistic talk commonly heard in the wider context and are sticky and hard to disregard.

In this instance I found myself making a pragmatic decision not to challenge such sexist remarks. My dilemma as a feminist researcher became one of setting participants' displays of hyper-masculinity to the side, whilst trying to see and relate to each man's unique subjectivity. This reflects the challenging reality of collaboration, I had to consciously check myself before entering into group work, reminding myself, each time, that my goal was to understand through dialogue the underlying gendered and classed experiences that led to their worldviews. This approach allowed me to continue to develop relationships with the men. The stories that emerged, through the photovoice process, illuminated lives which had been honed against a backdrop of social harm and violence which in turn produced, what Badboy termed, a destructive, oppressive and ultimately fragile 'hard-man' shield.

Badboy: You don't want to come across as soft, vulnerable, weak. Because you're afraid that other people will think that you're vulnerable and then, you know. That man's man of bein' tough on the exterior, of anythin' happens to my son and my family, I'm goin' to be the man. You feel like that would be taken away from you. So, you sort of say to yourself, 'Well I can't be vulnerable' ... sometimes you put on a front, the 'hard-man front'. It's an image. (Transcript group 3)

Photographs of their children evoked memories of the men's younger years and, prompted by me, gave rise to reflections on the shaping of their masculinity. During free-flowing group discussion, commonalities about the lines of power, which had shaped them as men, were identified. Families, place, the education system, social class, the media and religious institutions were all implicated as having deeply influenced ideas of what it meant to be a real man.

Reflecting the greater power of men in the wider social context (Connell, 1995: hooks, 2004), fathers were identified as having the most influence on their young masculinities and subsequently on their own approach to fatherhood. 
Pado: I'm talkin' about a bloke that's at home with his missus. He's two or three kids and like he's goin' from the way his father carried on when he was growin' up. His father done that and he's doin' what his father done.

Tommy: Well that's the biggest influence on men ... [Interrupted]

Pado: Yeah, the father, the father would have been. (Transcript group 1)

Emerging from their photovoice conversations the model of fatherhood they described defined men as breadwinners, as inexpressive and authoritarian. In their fathers' day, men were expected to provide and there was no expectation that they would look after children. That was women's work. Reflecting on their photographs they recognized the durable power of that model and uncovered together the complexity of their new situation as SAHF.

Jack: There it is. If the man is not workin' he is not a good provider. That's the way it is looked at. You are a bad provider for your family. It's not even that anyone has to say it to him. People know like. Maybe you're sittin' down in the pub and you're drinkin' and you hear people whisperin' and sayin' 'Ah Jaysus, you'd think he would be at home with his family or out looking for a job'. (Transcript group 2)

Prompted by their revealing images men slowly began to open up to one another, to share their desires to do fatherhood differently.

Messi: Bein' a father, from your own father, you'll always want to do somethin' different. Make it better all the time. From what you had from your own childhood, from your own father. You want to, you just want it better. Well as best you can. (Transcript group 2)

Through the display and discussion of photographs, participants and the researcher were introduced to the private lives of other men from their communities and new understandings emerged. A window opened into the intimate spaces of children's bedrooms, sitting rooms, kitchens, bathrooms and gardens.

Rory: There's a nice message on the wall there. I can't quite read it, somethin' about love?

Messi: This house is seasoned with love or somethin'. That would be the wife, she likes all these morals up so the kids are looking at these and we hope they are taking it on board and use it in their lives somewhere, you know.

Rory: It's a nice message! You must have stood up on the chair to take that!

Messi: I had to get up on a chair to take that! They're nearly all bigger than me an' anyway so I had to do that. [Laughter] (Transcript group 2) 
The photographs were pored over. Images of partners and children were brought to life through the words spoken by the men. They were inquisitive about each other's children.

Batman: See he's autistic.

Najib: And what age is he?

Batman: He's just eight. He hadn't talked for five years and he started, and as I says he loves maths now, he loves numbers.

Najib: Can he talk?

Batman: Perfect now. He can talk, he can communicate with you. He never shuts up! (Transcript group 3)

Listening to the workshop audio recordings I had the sense that participants got to know the lifeworlds of other men in a new way. "New angles of vision" (HesseBiber \& Piatelli, 2012, p. 560) were revealed through a multi-sensory encounter with the men's family lives and with their interior worlds.

Whilst responding to one another's evocative images men were conversing and connecting with one another and the more public form banter was gradually left aside. These were meaningful conversations where men expressed empathetic interest. They shared with one another something of the complexities and contradictions of their intimate selves, of what one participant termed their 'soft spots'. They spoke of the vulnerabilities of being a SAHF, of their desires for themselves and their families, of what mattered to them, of their values and commitments. Providing evidence of masculine subjectivities in transition, and alongside their compelling photographs, they allowed themselves to be seen by others and to engage in counter-hegemonic care-talk. Supported by photovoice, the research participants' narratives disrupted one-dimensional pathologized representations of fathers from working-class communities. The men emerged as caring, committed fathers who were determined to do their best for their children, often with scarce resources. The men were engaged in developing their subjectivities through connecting with others and the study revealed the diversity and complexity of masculinities. Research participants were heard to be tentatively imagining and constructing their own patterns of masculinity.

As the researcher I was struck by the power of the facilitated photovoice process to spark richly nuanced and revealing conversations amongst participants. The men were engaged in a reflexive adult learning environment where as one participant commented, they were 'getting the head working'. Prompted by the creative research process, participants were noticing life in a more acute and heightened way. They were heard to be critically examining assumptions and beliefs about their gendered construction and assessing such messages in their new situations as SAHF. Furthermore, they were questioning the usefulness of these gendered messages to the next generations. Many expressed enjoyment about the research process. They were 
developing learning skills that redressed experiences of educational inequalities of the past. They were expressing themselves, actively listening to one another and discovering they were not alone in their experiences. Collaboratively they were learning about the possibilities of change to unjust social structures.

My learning in terms of research methods reflected some of that of the research participants. Skilled facilitation and photovoice combined to construct an engaging, dynamic research process. The understanding that the research was both enjoyable and useful to the men evoked a strong feeling of personal satisfaction in me. It reaffirmed the power of creativity to bring to light nuanced understandings of complex social realities.

On reflection, and prompted by the men's openness I have observed that my own socially constructed and gendered shield as a 'smiling', 'soft-woman' was as deeply enmeshed in my identity as the men's hard-man shield. This has stretched my understanding of gender relationships and the mutuality of learning.

\section{CONCLUSION}

In the context of this study aspects of the method and process of photovoice emerged as congruent with the goals and practice of critical adult education. The starting point of both is that people and their experiences are of value. Adult education and photovoice both nurture a belief in the power of collective reflexivity and the importance of praxis-oriented learning for greater social justice. In this instance the process of analysis, reflection and transformation was at an individual and collective level. It stopped short of activism towards structural change and on one hand this is a limitation of the research. However, whilst the creative research process met participants where they were it did not leave them there.

Despite societal efforts that sought to shape them as hard-men, and enabled by the photovoice method and research approach, the men in this study tentatively allowed themselves to be vulnerable to one another. They actively engaged in counter-narratives of masculinity. The creative and thoughtful production of images of FLLC ignited deep engagement with the research topic. The immersive process involved an extended time commitment by participants and this had an impact on the quality of research relationships and, in turn, the emerging data. The very pace of the creative research method was unlike language based qualitative interviews. No instant responses to questions were expected. Rather, through the process of creating an image, participants had time and space away from the research site to consider their own meanings and understandings of the research topic.

Supported by the reflexive photovoice methodology the men in this study transformed initial presentations of themselves as stereotypical 'hard-men'. Photovoice not only facilitated the men to name their world, it also invited them to show their previously unseen worlds to one another and to imagine alternative scripts of masculinity for themselves and their children. 
In particular, the collective process of viewing and responding to the photographs sparked imaginations and gave rise to meaningful conversations. Images that showed children, wives and partners animated the private lives of the men and their families. Participants' curiosity about those in the photographs prompted the sharing of experiences and created an opportunity for the men to engage in revealing conversations which were characterized by affective expression. The men's stories gave rise to critical questioning of everyday classed and gendered experiences that were previously assumed to be 'natural'. Conversations tentatively rehearsed the envisioning of a more gender just world and provided insight into their power to make different choices for themselves. The creative, enabling and reflexive photovoice methodology proved to be a really useful research method. It helped to reveal and disrupt the lines of power that shaped masculinity and supported new masculine subjectivities to emerge.

\section{NOTE}

1 Participants chose their own pseudonyms.

\section{REFERENCES}

Allen, A. (2002). Power, subjectivity, and agency: Between Arendt and Foucault. Journal of Philosophical Studies, 10, 131-149.

Barry, U., \& Conroy, U. (2012). Ireland 2008-2012: Untold story of the crisis - Gender, equality and inequalities. Dublin: TASC.

Bengry-Howell, A., \& Griffin, C. (2012). Negotiating access in ethnographic research with 'hard to reach' young people: Establishing common ground or a process of methodological grooming? International Journal of Social Research Methodology, 15(5), 403-416.

Connell, R. W. (1995). Masculinities. Cambridge: Polity.

Connolly, B. (2008). Adult learning in groups. Berkshire: Open University Press.

Corridan, M. (2002). Moving from the margins. Dublin: Dublin Adult Learning Centre.

Dean, J. (1998). Feminist solidarity, reflective solidarity. theorizing connections after identity politics. Women and Politics, 18(4), 1-26.

De Brun, T., \& Du Vivier, E. (2007). Own goals and penalties: A study of the needs of socially excluded males in Dublin's Inner city. Dublin: Dublin Inner City Partnership.

Etherington, K. (2004). Becoming a reflexive researcher: Using ourselves in research. London: Jessica Kingsley Publishers.

Freire, P. (1972). Pedagogy of the oppressed. London: Penguin.

Freire, P. (1997). Pedagogy of hope. New York, NY: Continuum.

Grønnerød, J. S. (2004). On the meanings and uses of laughter in research interviews; Relationships between interviewed men and a woman interviewer. Nordic Journal of Youth Research, 12(1), 31-49.

Hegarty, A. (2017). Masculinity, fathers and family literacy: Glimpses behind the 'hard-man' front (Unpublished $\mathrm{PhD}$ thesis). Maynooth University, Maynooth.

Hegarty, A., \& Feeley, M. (2010). Taking care of family literacy work: An enquiry with parents about their experience of nurturing language and literacy in the home. Dublin: National Adult Literacy Agency.

Hesse Biber, S. N., \& Piatelli, D. (2012). The feminist practice of holistic reflexivity. The handbook of feminist research: Theory and praxis. New York, NY: Sage.

Hewett, C. (2015). Britain's most feckless father single again after splitting from latest girlfriend. Retrieved June 15, 2016, from http://www.irishmirror.ie/news/world-news/britains-most-fecklessfather-single-5491448 
hooks, b. (1994). Teaching to transgress: Education and the practice of freedom. Routledge: New York. hooks, b. (2004). The will to change. New York, NY: Washington Square Press.

Jon-Steiner, V. (1997). Notebooks of the mind: Exploration of thinking. Oxford: Oxford University Press. Karther, D. (2002). Fathers with low literacy and their young children. Reading Teacher, 56(2), 184-193. Luttrell, W., \& Chalfen, R. (2010). Lifting up voices of participatory visual research. Visual Studies, 25(3), 197-200.

Martino, W., \& Berrill, D. (2003). Boys, schooling \& masculinity: Interrogating the 'right' way to educate boys. Educational Review, 55(2), 99-119.

Mitchell, C. (2010). Doing visual research. London: Sage.

Nichols, S. (2002). Parents' construction of their children as gendered, literate subjects: A critical discourse analysis. Journal of Early Childhood Literacy, 2(2), 123-144.

Oliffe, J. L., \& Bottorff, J. L. (2007). further than the eye can see? Photo elicitation and research with men. Qualitative Health Research, 17(6), 850-858.

Reay, D. (1998). Classwork: Mothers' involvement in their children's primary schooling. London: UCL Press.

Reay, D. (2004). 'It's all Becoming a Habitus': Beyond the habitual use of habitus in educational research. British Journal of Sociology of Education, 25(4), 431-444.

Slutskaya, N., Simpson, A., \& Hughes, J. (2012). Lessons from photoelicitation: Encouraging working men to speak. Qualitative Research in Organizations and Management: An International Journal, $7(1), 16-33$.

Wang, C., \& Burris, M. A. (1997). Photovoice: Concept, methodology, and use for participatory needs assessment. Health, Education and Behaviour, 24(3), 369-387.

Wang, C., Yi, W., Tao, Z., \& Carovano, K. (1998). Photovoice as a participatory health promotion strategy. Health Promotion International, 13(1), 75-86. 